\title{
Dietary omega-3 fatty acids and locomotor activity in an animal model of attention deficit hyperactivity disorder (ADHD)
}

\section{Klaus W. Lange, Ewelina Makulska-Gertruda, Jakob Reisinger, Thomas-A. Sontag, and Joachim Hauser}

Department of Experimental Psychology, University of Regensburg, 93040 Regensburg, Germany

Corresponding author: Klaus $\mathrm{W}$. Lange, $\mathrm{PhD}$, Professor, Department of Experimental Psychology, University of Regensburg, 93040 Regensburg, Germany

Submission date: April 27, 2013; Acceptance date: June 3, 2013; Publication date: June 21, 2013

\section{ABSTRACT:}

Background: Attention deficit hyperactivity disorder (ADHD) is the most frequent behavioral disorder of childhood and is characterized by hyperactivity, attention problems and impulsivity. Pharmacological and behavioral therapies have been shown to be effective. In addition, the role of dietary compounds in the etiology and possibly the treatment of ADHD has attracted increasing attention. For example, the lack of dietary essential fatty acids has been suggested to be associated with symptoms of ADHD in humans.

Objective: To investigate the effects of omega-3 polyunsaturated fatty acids (n-3 PUFAs) on locomotor activity in the spontaneously hypertensive rat (SHR) which has been proposed as an animal model of ADHD.

Methods: Two groups of randomly assigned spontaneously hypertensive rats were fed with either n-3 PUFA-deficient or n-3 PUFA-enriched food (based on AIN93G) for six weeks and this was continued during the phase of behavioral testing. Locomotor activity was subsequently assessed using an open field test.

Results: The results showed a marked difference in locomotor activity between the two groups of SHRs. In comparison with rats fed with n-3 deficient food, the animals on an n-3 enriched diet showed a statistically significant decrease in motor activity as assessed by the distance traveled.

Conclusions: The present study demonstrates a marked reduction in locomotor activity following an n-3 PUFA-enriched diet in SHRs, i.e. the dietary enrichment with n-3 PUFAs reduced the motor activity in an established animal model of ADHD. Dietary n-3 PUFAs may therefore play a role in the pathophysiology of ADHD. 
Key words: omega-3 polyunsaturated fatty acids, attention deficit hyperactivity disorder, ADHD, animal model, spontaneously hypertensive rat, SHR, motor activity

\section{BACKGROUND:}

Attention deficit hyperactivity disorder (ADHD) is the most frequent behavioral disorder of childhood. The characteristic features of children and adolescents with ADHD are excessive motor activity, inattention and impulsiveness [1-4]. ADHD affects approximately 3-5 \% of children and adolescents worldwide, with a higher prevalence in boys [5-7]. Genetic, neurobiological, social and environmental factors have been discussed in regard to the etiology of $\operatorname{ADHD}[5,8,9]$.

Nutrition is thought to play an important role in the behavior and cognitive functioning of children and dietary factors in the etiology of ADHD have been discussed [10, 11]. For example, it has been suggested that suboptimal omega-3 polyunsaturated fatty acid (n-3 PUFA) levels may contribute to ADHD symptoms. The rise in consumption of processed foods and vegetable oils has markedly increased the intake of omega-6 (n-6) PUFAs in Western diets, while the consumption of n-3 PUFAs in fish, nuts and seeds has declined. The ratio of n-3:n-6 PUFAs has consequently decreased from about 1 in traditional diets to approximately 1:15 [12]. Some studies have reported that children with ADHD have reduced levels of blood n-3 PUFAs compared to matched healthy control subjects $[13,14]$

\section{INTRODUCTION:}

Spontaneously hypertensive rats (SHRs) were developed by inbreeding rats of the Wistar-Kyoto (WKY) strain. The SHR is one of the best studied animal models of ADHD. In comparison to WKY rats, SHRs show several behavioral alterations characteristic of ADHD, including hyperactivity, impulsivity, poor sustained attention and an impaired ability to withhold responses [15-19]. In the present study, we have investigated the effects of an n-3 PUFA-enriched diet versus an n-3 PUFA-deficient diet on locomotor behavior in SHRs using an open-field paradigm.

\section{ANIMALS AND METHODS:}

Animals. In the present study, 20 7-week-old male SHRs were used (Charles River, Sulzbach, Germany). The rats were housed in groups of five animals per cage and kept on a 12:12 h lightdark cycle (room temperature $22{ }^{\circ} \mathrm{C}$, humidity $50 \%$ ). They were given free access to water and the experimental diet, except for the behavioral testing period. At the beginning of the behavioral experiments water was provided ad libitum but food was restricted in order to prepare the animals for the experiments and to increase their motivation.

The rats were at randomly assigned to two groups, i.e. group 1 (n-3 PUFA-enriched, n=10) received a diet enriched in n-3 PUFAs (Ssniff, Soest, Germany; based on AIN93G, for details see Table 1), while group 2 (n-3 PUFA-deficient, $n=10$ ) was fed with a diet deficient in $n-3$ PUFAs (see Table 1). The experimental diets were provided for six weeks and during the subsequent phase of behavioral testing. 
Table 1. Fatty acid composition of the experimental diets based on the AIN93G composition (source: Ssniff Spezialdiäten, Soest, Germany)

\begin{tabular}{lll}
\hline & n-3 PUFA-enriched diet & n-3 PUFA-deficient dieT \\
\hline Energy (Atwater), MJ/kg* & 17.1 & 17.1 \\
kJ\% protein & 18 & 18 \\
kJ\% carbohydrates & 60 & 60 \\
kJ\% fat & 22 & 22 \\
& & \\
Fatty acids, \% of diet & & \\
C 6:0 & 0.05 & 0.05 \\
C 8:0 & 0.59 & 0.62 \\
C 10:0 & 0.47 & 0.49 \\
C 12:0 & 3.48 & 3.64 \\
C 14:0 & 1.35 & 1.41 \\
C 16:0 & 0.84 & 0.85 \\
C 18:0 & 0.29 & 0.28 \\
C 20:0 & 0.01 & 0.01 \\
C 18:1 & 0.82 & 0.77 \\
C 18:2 n6 & $\mathbf{1 . 5 4}$ & $\mathbf{1 . 5 8}$ \\
C 18:3 n3 & $\mathbf{0 . 2 7}$ & $\mathbf{0 . 0 1}$ \\
& & \\
\hline
\end{tabular}

* Physiological fuel value

Apparatus: The rats' locomotor activity was measured in an open field. The open field used consisted of a rectangular arena (size: $82.5 \times 82.5 \mathrm{~cm}$ with walls $40 \mathrm{~cm}$ high), made of dark gray synthetic material. The locomotor activity was recorded by a fixed digital video system. This data was digitized and analyzed using the video tracking system ETHOVISION 3.0 (Noldus, Wageningen, The Netherlands). The distance traveled in the open field over 15 minutes was recorded.

Procedure: Rats were tested once daily for six consecutive days. Each rat was individually placed in the center of the open field and allowed to explore freely for 15 minutes. Prior to each trial all open-field surfaces were cleaned with $70 \%$ alcohol in order to remove odors and/or residues of rats tested previously. The rats were tested each day in random order. The animals' body weight was measured daily in order to ensure normal weight gain and to prevent a weight loss of more than $10 \%$. At the time of behavioral testing, there were no significant differences in body weight between the two experimental groups.

Statistics: The statistical analysis of differences between the two groups (n-3 PUFA-enriched and n-3 PUFA-deficient) was performed with Mann-Whitney U-test using the Statistical Package for Social Sciences 17.0 (SPSS) for Windows. An alpha level of .05 was applied. 
Ethics: This study was performed in accordance with national laws (German Law on Protection of Animals) and European laws, and the principles of laboratory animal care (NIH publication No. 86-23, revised 1985).

\section{RESULTS:}

The locomotor activity on six consecutive days (i.e. the distance travelled within 15 minutes) of SHRs following consumption of n-3 deficient or $n-3$ enriched diet for six weeks (plus six days of testing) is given in Table 2. The distance travelled of the n-3 deficient SHR group was significantly increased on days 2, 4, 5, 6 and over the total of 6 days when compared to the animals fed with the $\mathrm{n}-3$ enriched diet.

Table 2. Distance travelled in the open field of the n-3 PUFA-deficient and n-3 PUFA-enriched SHR groups (means \pm standard errors)

\begin{tabular}{lllll}
\hline & $\mathrm{n}-3$ PUFA-deficient & $\mathrm{n}$-3 PUFA-enriched & $\mathrm{p}$-value & z-value \\
\hline Day 1 & $5858.6 \pm 156.6$ & $5526.0 \pm 191.2$ & 0.226 & -1.21 \\
Day 2 & $6114.8 \pm 242.5 *$ & $4997.1 \pm 257.6$ & 0.013 & -2.50 \\
Day 3 & $5014.1 \pm 181.2$ & $5108.5 \pm 251.4$ & 1 & 0 \\
Day 4 & $5664.2 \pm 158.7 *$ & $4843.0 \pm 162.9$ & 0.003 & -2.95 \\
Day 5 & $5333.9 \pm 320.3 *$ & $4381.6 \pm 151.0$ & 0.023 & -2.27 \\
Day 6 & $5549.4 \pm 317.2 *$ & $4578.7 \pm 205.0$ & 0.041 & -2.04 \\
& & & & \\
Days 1-6 (mean) & $\mathbf{5 5 8 9 . 2} \pm \mathbf{1 6 5 . 5} *$ & $\mathbf{4 9 0 5 . 8 0} \pm \mathbf{1 3 0 . 2}$ & $\mathbf{0 . 0 0 7}$ & $\mathbf{- 2 . 7 2}$ \\
\hline
\end{tabular}

$* \mathrm{p} \leq .05$ compared to $\mathrm{n}-3$ PUFA-enriched group

\section{DISCUSSION:}

Long-chain PUFAs are essential for the central nervous system, e.g. the most predominant n-3 PUFA in the brain, docosahexaenoic acid (DHA) [20, 21], increases cellular membrane flexibility and is involved in the regulation of neurotransmission, myelination, and other cellular activities. An impoverished n-3 PUFA diet in rodents over several generations has been shown to result in a 50 to $80 \%$ deficit in brain DHA phospholipids and in cognitive deficits including the performance in spatial learning and other learning tasks [22-24].

Dietary factors including the dietary lack of n-3 PUFAs have been discussed in regard to dyfunctions found in ADHD [for review of animal research see 25]. Several clinical trials with mixed results have been conducted to investigate whether some behavioral or cognitive symptoms of children with ADHD can be improved by long-chain PUFA supplementation [26]. Locomotor hyperactivity is the most easily discerned symptom of ADHD. The present study investigated the effects of a diet rich or impoverished in n-3 PUFAs on locomotor activity in rats using an open-field paradigm. We have used SHRs which have been proposed as an animal model of ADHD [e.g. 19]. 
The present results showed a marked difference in locomotor activity between the two groups of SHRs. In comparison with rats fed with n-3 PUFA-deficient food, the animals on an n3 PUFA-enriched diet showed a statistically significant decrease in motor activity as assessed by the distance traveled in the open field.

Previous studies investigating the role of dietary PUFAs on locomotion in rodents reported inconsistent findings. A study in mice investigating the effects of a diet deficient in $\alpha$-linolenic acid followed or not by supplementation with phospholipids rich in n-3 PUFAs found no significant effect between diet groups on open-field motor activity [27]. A fish oil enriched diet was reported to reduce ambulatory activity in Wistar rats [28]. In SHRs, dams were given n-3 PUFA-enriched feed during pregnancy and their offspring continued on this diet [29]. This study showed an n-3 PUFA-induced reduction in spontaneous locomotion.

Given the hypothesis that SHR is a valid animal model of ADHD symptoms including hyperactivity [for critical review see 30], one could conclude from our data that the diet enriched with n-3 PUFAs reduced the rats' hyperactivity. However, the present results were obtained by comparison with animals fed with n-3 PUFA-deficient food. Further studies are therefore needed in order to establish if the (hyper) activity of SHRs can also be ameliorated when the animals are fed with a balanced diet. In addition, it remains of interest whether other ADHD core symptoms such as inattention or impulsivity are affected by dietary n-3 PUFAs.

\section{CONCLUSIONS:}

The present study demonstrated a marked reduction in locomotor activity following an n-3 PUFA-enriched diet in SHRs, i.e. the dietary enrichment with n-3 PUFAs reduced the activity in an established animal model of ADHD when compared with an n-3 PUFA-deficient diet. Dietary n-3 PUFAs appear to affect locomotor activity in rats and may play a role in the pathophysiology of ADHD.

Competing Interests: The authors have no financial interests or conflicts of interest.

Authors' Contributions: All authors contributed to this study.

Abbreviations: ADHD, attention deficit hyperactivity disorder; DHA, docosahexaenoic acid; n3 PUFA, omega-3 polyunsaturated fatty acid; n-6 PUFA, omega-6 polyunsaturated fatty acid; SHR, spontaneously hyperactive rat.

\section{REFERENCES:}

1. Lange KW, Reichl S, Lange KM, Tucha L, Tucha O. The history of attention deficit hyperactivity disorder. Atten Defic Hyperact Disord 2010; 2(4): 241-55.

2. Tucha O, Prell S, Mecklinger L, Bormann-Kischkel C, Kübber S, Linder M, Walitza S, Lange KW. Effects of methylphenidate on multiple components of attention in children with attention deficit hyperactivity disorder. Psychopharmacology 2006; 185: 315-326.

3. Tucha O, Walitza S, Mecklinger L, Sontag TA, Kübber S, Linder M, Lange KW. Attentional functioning in children with ADHD - predominantly hyperactive-impulsive 
type and children with ADHD - combined type. Journal of Neural Transmission 2006; 113: 1943-1953.

4. Lange KW, Tucha L, Walitza S, Gerlach M, Linder M, Tucha O._Interaction of attention and graphomotor functions in children with attention deficit hyperactivity disorder. $\mathrm{J}$ Neural Transm Suppl 2007; 72: 249-59.

5. Barkley RA. Attention-Deficit Hyperactive Disorder: a handbook for diagnosis and treatment. London: Guilford Press, 2006.

6. Clements KM, Girard TA, Xing HC, Wainwright PE. Spontaneously hypertensive and Wistar Kyoto rats differ in delayed matching-to-place performance and response to dietary long-chain polyunsaturated fatty acids. Dev Psychobiol 2003; 43: 57-69.

7. Paule M, Rowland A, Ferguson S, Chelonis J, Tannock R, Swanson J, Castellanos F. Attention Deficit/Hyperactivity Disorder: Characteristics, Interventions, and Models. Neurotoxicol Teratol 2000; 22: 631-651.

8. Biederman J, Faraone SV. Attention-deficit/hyperactivity disorder. The Lancet 2005; 366(9481): 237-248.

9. Vancassel S, Blondeau C, Lallemand S, Chador M, Linard A, Lavialle M, DelluHagedorn F. Hyperactivity in the rat is associated with spontaneous low level of n-3 polyunsaturated fatty acids in the frontal cortex. Behav Brain Res 2007; 180: 119-126.

10. Wainwright PE. Dietary essential fatty acids and brain function: a developmental perspective on mechanisms. Proc Nutr Soc 2002; 61: 61-69.

11. Schuchardt JP, Huss M, Stauss-Grabo M, Hahn A. Significance of long-chain polyunsaturated fatty acids (PUFAs) for the development and behaviour of children. Eur J Pediatr 2010; 169: 149-164.

12. Simopoulos AP. The importance of the ratio of omega-6/omega-3 essential fatty acids. Biomed Pharmacother 2002; 56(8): 365-79.

13. Richardson AJ. Omega-3 fatty acids in ADHD and related neurodevelopmental disorders. Int Rev Psychiatry 2006; 18(2): 155-72.

14. Young G, Conquer J. Omega-3 fatty acids and neuropsychiatric disorders. Reprod Nutr Dev 2005; 45(1): 1-28.

15. Berger DF, Sagvolden T. Sex differences in operant discrimination behaviour in an animal model of attention-deficit hyperactivity disorder. Behav Brain Res 1998; 94(1): 73-82.

16. Boix F, Qiao SW, Kolpus T, Sagvolden T. Chronic L-deprenyl treatment alters brain monoamine levels and reduces impulsiveness in an animal model of AttentionDeficit/Hyperactivity Disorder. Behav Brain Res 1998; 94(1): 153-62.

17. Johansen EB, Sagvolden T. Response disinhibition may be explained as an extinction deficit in an animal model of attention-deficit/hyperactivity disorder (ADHD). Behav Brain Res 2004; 149(2): 183-96.

18. Russell VA, de Villiers AS, Sagvolden T, Lamm MC, Taljaard JJ. Methylphenidate affects striatal dopamine differently in an animal model for attention-deficit/hyperactivity disorder--the spontaneously hypertensive rat. Brain Res Bull 2000; 53(2): 187-92. 
19. Sagvolden T. Behavioral validation of the spontaneously hypertensive rat (SHR) as an animal model of attention-deficit/hyperactivity disorder (AD/HD). Neurosci Biobehav Rev 2000; 24: 31-39.

20. Sastry PS. Lipids of nervous tissue: composition and metabolism. Prog Lipid Res 1985; 24(2): 69-176.

21. Spector AA. Plasma free fatty acid and lipoproteins as sources of polyunsaturated fatty acid for the brain. J Mol Neurosci 2001; 16(2-3): 159-65.

22. de Souza AS, Pacheco Lda C, Castro Pda S, Hokoç JN, Rocha MS, do Carmo Md. Brain fatty acid profiles and spatial learning in malnourished rats: effects of nutritional intervention. Nutr Neurosci 2008; 11(3): 119-27.

23. Fedorova I, Hussein N, Baumann MH, Di Martino C, Salem N Jr. An n-3 fatty acid deficiency impairs rat spatial learning in the Barnes maze. Behav Neurosci 2009; 123(1): 196-205.

24. Vancassel S, Aïd S, Pifferi F, Morice E, Nosten-Bertrand M, Chalon S, Lavialle M. Cerebral asymmetry and behavioral lateralization in rats chronically lacking $\mathrm{n}-3$ polyunsaturated fatty acids. Biol Psychiatry 2005; 58(10): 805-11.

25. Transler C, Mitchell S, Eilander A. Could polyunsaturated fatty acids deficiency explain some dysfunctions found in ADHD? Hypotheses from animal research. J Atten Disord 2013; 17(1): 20-28.

26. Transler C, Eilander A, Mitchell S, van de Meer N. The impact of polyunsaturated fatty acids in reducing child attention deficit and hyperactivity disorders. J Atten Disord 2010; 14(3): 232-46.

27. Carrié I, Clément M, de Javel D, Francès H, Bourre JM. Phospholipid supplementation reverses behavioral and biochemical alterations induced by n-3 polyunsaturated fatty acid deficiency in mice. J Lipid Res 2000; 41(3): 473-80.

28. Chalon S, Delion-Vancassel S, Belzung C, Guilloteau D, Leguisquet AM, Besnard JC, Durand G. Dietary fish oil affects monoaminergic neurotransmission and behavior in rats. J Nutr 1998; 128: 2512-9.

29. Dervola KS, Roberg BA, Wøien G, Bogen IL, Sandvik TH, Sagvolden T, Drevon CA, Johansen EB, Walaas SI. Marine omega-3 polyunsaturated fatty acids induce sex-specific changes in reinforcer-controlled behaviour and neurotransmitter metabolism in a spontaneously hypertensive rat model of ADHD. Behav Brain Funct 2012; 8: 56.

30. Sontag TA, Tucha O, Walitza S, Lange KW. Animal models of attention deficit/hyperactivity disorder (ADHD): a critical review. Atten Defic Hyperact Disord 2010; 2(1): 1-20. 